\title{
Application of Artificial Intelligence in Marketing: A Conceptual Study
}

\footnotetext{
${ }^{* 1}$ Mohammad Sirajuddin, ${ }^{2}$ P Jagannadharao

1,2 Assistant Professor, Department of Business Administration, CMR College of Engineering \& Technology, Kandlakoya, Medchal Road, Hyderabad, Telangana, India

*1siraj0629@ rediffmail.com

${ }^{2}$ laxmijagan2003@gmail.com
}

Received: $2^{\text {nd }}$ September 2020, Accepted: $4^{\text {th }}$ November 2020, Published: $31^{\text {st }}$ December 2020

\begin{abstract}
Lately, man-made brainpower (AI) has turned into an arising pattern in various fields: science, business, medication, car and instruction. Simulated intelligence has likewise arrived at showcasing. The point of paper is to explore how profoundly artificial intelligence is applied in advertising and what suggestions there are showcasing specialists. Creators expressed two exploration questions - which spaces of artificial intelligence are utilized in advertising and what suggestions artificial intelligence conveys for showcasing chiefs. To address those inquiries, the creators directed exploration on optional information with artificial intelligence models utilized for promoting reason. The investigation of accumulated models shows that artificial intelligence is broadly brought into the advertising field; however the applications are at the functional level. This might be the impact of cautious execution of the new innovation, still at the degree of exploring different avenues regarding it. The vulnerability of the result of artificial intelligence execution might influence the alert in incorporating these advancements too. Assembled models demonstrated that artificial intelligence impacts all parts of promoting blend affecting both purchaser esteem conveyance just as the advertising association and the board. The paper conveys suggestions for business, particularly thoughts regarding carrying out AI into promoting, planning advancements and the thoughts on the most proficient method to consolidate new abilities into advertising group needed innovation.
\end{abstract}

Keywords: Man-made reasoning, Advertising, Application, Suggestions

\section{Introduction}


Man-made thinking has of late transformed into an incredibly notable subject in the space of the leaders and exhibiting sciences, but, incredibly, the works on its headway in various areas of science have been proceeding reliably for north of 50 years. All through the long haul, man-made consciousness has been appearing in and evaporating from the spotlight dependent upon the level of its movement and the addition in its normal suitability. The premium in and the expansive discussion on man-made consciousness are achieved by the chief wide-scale business usages of man-made brainpower, which have shown the potential and the limits of this development moreover in the space of advancing.

The quick improvement of man-made consciousness has been possible by virtue of the progress of the scholarly instruments of man-made brainpower and of capacities of machines to learn subject to the got data (Lieto, Bhatt, Oltramari, and Vernon, 2017), similarly as in view of the probability to make currently non-existing information (Grawal, Gans, and Goldfarb, 2017). The power of man-made brainpower furthermore lies in the scope of treatment of various designs of data - beside numerical data, mechanized thinking cycles texts, pictures, and sounds, outfitting them with significance and relevance for extra examinations (Dhar, 2016).

Man-made insight has been up until this point drawing the thought of originators, IT trained professionals, and specialists, but is as of now moving outer its regular spaces of occasion, leaving a certainly more grounded engrave in the field of the load up and publicizing. The reliably extending proportion of purchaser data open on the web, in huge data systems or PDAs, makes artificial intelligence transform into a critical accomplice of promoting, as it relies upon data examination in basically every space of its application.

Advancing endeavors data for the most part - from customer needs research, market assessments, customer encounters, and competition information through pursuing activities in various correspondence or transport channels to assessing the results and effects of the took on procedures. Publicizing transforms into a trademark beneficiary of making information advancement (Mazurek, 2011a, 2011b, 2014). The closeness of the two regions makes it possible to achieve a helpful energy sway. Along these lines, it has all the earmarks of being basic to push the ability of man-made intellectual prowess and of the open computerized reasoning based instruments and to discuss the business employments of man-made brain power in the space of advancing. The article is disengaged into four areas. 
The underlying portion fuses the imperative implications of the considerations associated with artificial intelligence. The part being an effect of an examination of the assembled models, gives a depiction of spaces of artificial intelligence impact on advancing. The article covers the possibilities and risks fundamental the utilization of artificial intelligence in showcasing action.

Artificial Intelligence overview: Man-made reasoning gets from data innovation. It is regularly utilized reciprocally with ideas like mechanization or robotization. It likewise will in general be mistaken for artificial intelligence or calculation application. As per Oxford Dictionary, artificial intelligence is "the hypothesis and advancement of PC frameworks ready to perform errands ordinarily requiring human insight, for example, visual discernment, discourse acknowledgment, navigation, and interpretation between dialects" ("man-made reasoning | Definition of man-made brainpower in English. The innovation dependent on man-made brainpower can copy the intellectual capacities that we trait to the human psyche, including the capacity to tackle issues and learn. The job and of artificial intelligence is to process and recognize the procured information and afterward to play out specific undertakings. This is the meaning of the alleged Artificial Narrow Intelligence, what capacities and completes errands in a characterized region.

The second kind of artificial intelligence is Artificial General Intelligence, whose extent of mental ability is practically identical to that of the human mind. The current capability of artificial intelligence works in a thin region, and assignments are performed because of the headway of three advances: artificial intelligence, profound learning, and regular language handling. Artificial intelligence has taken to a more elevated level, one over the degree of adhering to a bunch of predefined guidelines. Accordingly, ML has changed the job of calculations have been utilized such a long ways with AI.

ML has empowered PCs to learn without anyone else dependent on the accessible information by setting up joins between individual bits of information. Because of these abilities, ML makes it conceivable to make determinations and structure speculations based on performed examinations (McIlwraith, Marmanis, and Babenko, 2017). ML comes in many structures and might be introduced as example acknowledgment, measurable displaying, information investigation, information disclosure, prescient examination, information investigation, versatile frameworks, 
self-putting together frameworks, and some more.

Profound learning is a more elevated level since dependent on learning calculations don't should be overseen physically. Exploiting large information and registering force (of, for example server ranches, power, distributed computing), makes it conceivable to unravel and give the outcome to another snippet of data right away.

Normal language handling is one of the uses of focusing on discourse acknowledgment. Numerous long stretches of exploration in this space have made it conceivable to deal with a lot of information (text tests) that go about as wellsprings of the specific circumstance, the jargon, the sentence structure, and the semantic importance.

Progressions led in those advances have empowered the improvement of artificial intelligence in the space of voice, text, and picture acknowledgment, independent direction, and independent robots and vehicles. Commonsense application can be met for every one of these spaces. Voice acknowledgment is accessible, for instance, in cell phones (for example Siri, Google Assistant).

Text acknowledgment arrangements are utilized as remote helpers who convey fast responses (for example Deakin University and IBM Watson). Picture acknowledgment is utilized for installment endorsement, on account of correlation face picture the framework can make installments (for example pecking order KFC). Dynamic framework is accessible for instructive reason - IBM Elements is devoted for instructors to help them in understudy evaluation and to convey makes suggested individual improvement way for every understudy. At long last, independent robots and vehicles are utilized in the stockrooms to deal with the stock (for example in Amazon Kiva framework).

Marketing mix: American Marketing Association endorsed another adaptation of advertising definition. As per the affiliation "advertising is the movement, set of establishments, cycles for making, conveying, conveying, and trading contributions that have an incentive for clients, customers, accomplices, and society in general".

The basic part of advertising is the worth conveyance to clients while the worth might address distinctive item angles like merchandise, thoughts, administrations, data, or any sort of arrangement that satisfy client needs.

McCarthy proposed "advertising blend" as a calculated structure making an interpretation of showcasing arranging into training. However the advertising 
blend is certainly not a logical hypothesis, its apparatuses can foster both long haul procedures and transient strategic showcasing programs. McCarthy refined past Borden's origination of fulfilling the objective market. He pulled together Borden's 12 components (item arranging, valuing, marking, channels of circulation, individual selling, publicizing, advancements, bundling, show, overhauling, actual dealing with, reality finding and examination) into four components, called4Ps: item, value, advancement, and spot. There were further headways made inside the showcasing blend idea, for example, adding another Ps - individuals, processes, and actual proof. However the possibility of 4Ps is still generally utilized and acknowledged.

\section{Methodology}

In light of the emerging examples of man-made consciousness application in the business district, the mark of this paper is to overview the computerized reasoning execution in the field of advancing. The goal of the assessment is to assess the degree of man-made consciousness application inside exhibiting mix and notice answers to the investigation questions: do all spaces of manmade reasoning voice, text, picture affirmation, route, autonomous vehicles and robots track down application in publicizing how kind of ideas treats knowledge make in advancing practice. To react to these requests, the makers decided to lead assistant data investigation to gather examples of man-made reasoning application.

The process for social occasion computerized reasoning application was made in two phases. The underlying advance was a consideration on review the displaying passages to gather man-made brainpower application in advancing. The resulting advance was the endorsement of picked models by attesting gathered models with the information on the association site or in the authority articulation of each model. There was no limitation related with the model region; the goal of the discretionary investigation was to accumulate any outline of man made consciousness application. The presented closes rely upon the outcomes of the makers' assessment of aggregated models.

\section{Results}

To address the main examination question, (do all spaces of artificial intelligence track down application in promoting creators aggregated all approved models assembled by the five artificial intelligence regions which 
are introduced in Table 1. For each referenced artificial intelligence region (text, voice, picture acknowledgment, navigation, independent vehicles and robots) creators have tracked down artificial intelligence application in promoting While text acknowledgment, picture acknowledgment, dynamic advances are generally utilized, the voice innovation, just as independent vehicles and robots, are not really famous. This can be brought about by the more prominent intricacy of the two advances. In addition, independent vehicles and robots are all the more frequently seen as a piece of Industry 4.0 space than promoting. In this way it is only from time to time apparent as a method of making and creating advancements in deals channel the executives, promoting enhancement or conveying client care which are set in a showcasing blend program inside the 'place' space.

To address the subsequent exploration question (what sort of suggestions does artificial intelligence make in promoting practice?) creators led an investigation of accumulated models and caused an amalgamation of how the guides to mirror the advertising blend. Ends are introduced in Table 2. Each approved models shows that artificial intelligence sways every space of advertising blend program.

This fining is particularly significant for specialists who are answerable for creating advancements as artificial intelligence impact the entire range of showcasing action. It is worth focusing on that the space of 'place' requires collaboration with Industry 4.0 subject matter expert, as independent vehicle and robots assume a urgent part in making new deals channels and new client support. Furthermore, artificial intelligence applications that broaden the center item require advancement configuration way to deal with observe the experiences that match thoughts going past the item or smooth classification. This is significant for executing artificial intelligence inside 'item' and 'advancement' regions in the promoting blend.

Table 1: Area of the impact of artificial intelligence on marketing mix

\begin{tabular}{|c|c|c|c|}
\hline Product & Price & Promotion & Place \\
\hline $\begin{aligned} & \text { 1. } \text { New product } \\
& \text { development } \\
& \text { 2. } \\
& \text { 3. } \text { Recomsonalization } \\
& \mathrm{n} \\
& \text { 4. } \text { Value } \\
& \text { 5. } \text { category }\end{aligned}$ & $\begin{array}{l}\text { 1.Price } \\
\text { Managem } \\
\text { ent }\end{array}$ & $\begin{array}{l}\text { 1. Experience } \\
\text { 2. Communid } \\
\text { on } \\
\text { 3. Benefits } \\
\text { 4. Categories } \\
\text { 5. Impact } \\
\text { 6. Satisfactior }\end{array}$ & $\begin{array}{ll}\text { 1. } & \text { Convenient } \\
\text { 2. } & \text { Sales } \\
\text { 3. } & \text { Service } \\
\text { 4. } & \text { Automation } \\
\text { 5. } & \text { Support } \\
\text { 6. } & \text { Channel } \\
\text { 7. } & \text { merchandize }\end{array}$ \\
\hline
\end{tabular}


The examination of the gathered cases shows that AI exercises affect showcasing. From one perspective, the recipient of changes is the customer, however on the other, new arrangements influence the total of the sought after advertising exercises.

\section{The impact of artificial intelligence on consumers: As the}

Internet has achieved many benefits according to the purchaser's perspective, like programmed proposals and important item ideas or client support personalization, artificial intelligence goes above and beyond and offers new open doors in showcasing movement. The examination of the gathered instances of the use of artificial intelligence in advertising shows an entire range of benefits that artificial intelligence offers to buyers:

Advantageous speedier store time because of further developed cycles (for example programmed installments, the better nature of web search tools, every minute of every day client support).

New purchaser experience by means of mass-scale hyper-personalization, later deals administration that makes extra worth going past the fundamental item.

Another element of shopper product affiliation conveyed by building shock and enjoyment limited post-buy disharmony on account of the likelihood to test the considered item practically, end of the course of classification learning, lastly exploiting benchmarking against different clients.

The effect of AI on advertising the board: With regards to promoting the executives, AI essentially affects contemporary practices, and will certainly require another way to deal with errands satisfied in showcasing groups:

End of relentless and tedious exercises. Simulated intelligence robotizes normal and repeatable errands (for example information assortment and investigation, picture search and transformation/handling).

Greater meaning of imaginative and vital exercises for exact examinations performed by AI expands the job of innovative and vital exercises to construct upper hand.

Plan developments computer based intelligence reclassify the manner in which the worth is conveyed to the client and increment the job of tracking down new arrangements through plan.

For growing new capabilities in the group: Artificial intelligence requires consolidating information researcher abilities just as a comprehension of the 
new innovation prospects in the showcasing group.

One more promoting environment: The intricacy of artificial intelligence expands the job of organizations delivering artificial intelligence arrangements. Because of the current degree of artificial intelligence progression, there is a need to foster another model of participation with artificial intelligence substances offer information designing devices.

\section{Conclusion}

The assessment affirmed that artificial intelligence is applied in numerous spaces of promoting. The business arrangements dependent on it exploit every one of the five artificial intelligence regions: picture acknowledgment, text acknowledgment, navigation, voice acknowledgment and independent robots and vehicles. While the initial three are applied widely in promoting, the examples down to earth use of voice acknowledgment are uncommon and created by the greatest tech organizations have huge scope. Additionally, the independent vehicles and robots are not really continuous arrangement, as this space is substantially more associated with industry than advancement plan inside the advertising blend.

Artificial intelligence in showcasing is in general be as of now carried out at the functional level, ordinarily as oddball drives or exercises. This might result from the way that we are managing the main examples of the useful utilization of artificial intelligence, and organizations are cautious with executing the new innovation, exploring different avenues regarding it. The expenses connected with the improvement of new ideas and the vulnerability of the result of their execution might influence the alert in trying these developments too.

While breaking down item ubiquity, for example of sales force. Einstein and Albert artificial intelligence, it appears to be the primary executions rouse trust to artificial intelligence arrangements and organizations are more ready to exploit those assuming positive aftereffects of their application.

The examination of gathered models shows that artificial intelligence offers another quality to hopper's life. All day, every day client assistance, hyper customized arrangements, more helpful shopping, or the likelihood to try not to settle on some unacceptable decision all add to another aspect in the space of the showcasing association. 


\section{References}

1. Alpaydin, E. (2016). Machine Learning. MIT Press

2. Artificial intelligence |Definition of artificial intelligence in English by Oxford Dictionaries. (2019)

3. Bennett, A. R. (1997). The five Vs-a buyer's perspective of the marketing mix. Marketing Intelligence \& Planning, 15(3),151156

4. Booms, B. H., Bitner, B. J.(1980). Marketing strategies and organization structures for service firms. In Donnelly, J. \& George W. R. (Eds.), Marketing of services. American Marketing Association, p. 47-51

5. Dhar,V.(2016).The Future of Artificial Intelligence. Big Data,4(1),5-9, https://doi.org/10.1089/big.2016.29004.vda

6. Domingos, P. (2016). Naczelny Algorytm: Jak jego odkrycie zmieni nasz świat. Helion, Gliwice

7. Grawal, A.Gans, J. S., \& Goldfarb, A.(2017). What to Expect From Artificial Intelligence. MIT Sloan Management Review. Retrieved August, 10, 2018, from https://sloanreview.mit.edu/article/what-to-expect-from-artificialintelligence/

8. Grewal, D., Roggeveen, A. L., \& Nordfält, J.(2017).The future of retailing. Journal of Retailing, 93(1), 1-6. https://doi.org/10.1016/j.jretai.2016.12.008

9. Grönroos, Ch. (2006), On defining marketing: finding a new roadmap for marketing. Marketing Theory, 6(4), 395-417

10. Haridy, R. (2017). 2017: The year AI beat us at all our own games. Retrieved May, 10, 2018, from https://www.google.pl/url?sa=t\&rct=j\&q=\&esrc=s\&source=web $\& c d=2 \& c a d=r j a \& u a c t=8 \& v e d=2$ ahUKEwi3qejh $88 \mathrm{PcAhXBA50}$ KHXjyDoYQFjABegQIARAB\&url=https\%3A\%2F\%2F\%2Fai2017-beating-humans games\%2F52741\%2F\&usg=AOvVaw0ynvQnvrHHNWMIs5LvY FK4

11. https://en.oxforddictionaries.com/definition/artificial intelligence

12. Jordan,M. I. \& Mitchell, T. M. (2015). Machine learning: Trends, perspectives, and prospects. Science, 349(6245), 255-260. https://doi.org/10.1126/science.aaa8415

13. Lieto, A., Bhatt, M., Oltramari, A., \& Vernon, D. (2017). The role of cognitive architectures in general artificial intelligence. Cognitive Systems Research, 48,1-3, ttps://doi.org/10.1016/j.cogsys.2017.08.003.

14. Mlot, S.(2018). AI Beats Human Lawyers at Their Own Game. 
Retrieved May, 10, 2018, from https://www.google.pl/url?sa=t\&rct=j\&q=\&esrc=s\&source=web $\& \mathrm{~cd}=14 \& \mathrm{cad}=\mathrm{rja} \&$ uact $=8 \&$ ved $=2$ ahUKEwi3qejh88PcAhXBA5oKHXjyDoYQFjANegQIAxAB\&u $\mathrm{rl}=\mathrm{https} \% 3 \mathrm{~A} \% 2 \mathrm{~F} \% 2 \mathrm{Fwww}$.geek.c om\%2Ftech\%2Fai-beatshuman-lawyers-at-their-own-game1732154\%2F\&usg=AOvVaw02zOiXuratoHCB8YfsmLQV

15. Mazurek, G. (2011b). Virtualization of marketing - conceptual model. In Proceedings of the 2011 International Conference on Marketing Studies (ICMS2011), Academy of Taiwan Information Systems Research (ATISR), Kuala Lumpur, 9-11th September, 220-229

16. Mazurek, G. (2014). Network Value Creation through Marketing, Management \& Business Administration. Central Europe, 22(4), 70-77. https://doi.org/10.7206/mba.ce.20843356.120

17. McIlwraith D., Marmanis H., \& Babenko D. (2017). Inteligentna sieć. Algorytmy przyszłości. Helion, 2nd edition, Gliwice, p. 27

18. Moncrief, W. C. (2017). Are sales as we know it dying ... or merely transforming? Journal of Personal Selling \& Sales Management, $37(4)$

271-279, https://doi.org/10.1080/08853134.2017.1386110

19. Palmer, A. (2004). Introduction to Marketing - Theory and Practice. UK: Oxford University Press. Shanahan, M. (2015). The Technology Singularity. MIT Press.

20. Simonite, T. (2018). AI beat humans at reading! Maybe not. Retrieved May, 10, 2018, from https://www.google.pl/url?sa=t\&rct=j\&q=\&esrc=s\&source=web $\& \mathrm{~cd}=17 \& \mathrm{cad}=\mathrm{rja} \&$ uact $=8 \& \mathrm{ved}=2$ ahUKEwi3qejh88PcAhXBA5oKHXjyDoYQFjAQegQIBxAB\&u $\mathrm{rl}=\mathrm{https} \% 3 \mathrm{~A} \% 2 \mathrm{~F} \% 2 \mathrm{Fwww}$.wired.c om\%2Fstory\%2Fai-beathumans-at-reading-maybenot\%2F\&usg=AOvVaw0b1rNX76rschfKgbWprQsz

21. Sterne, J. (2017). Artificial Intelligence in Marketing, Practical Applications. Wiley and SAS Business Series

22. Syam, N., \& Sharma, A.(2018) Waiting for a sales renaissance in the fourth industrial revolution: Machine learning and artificial intelligence in sales research and practice. Industrial Marketing Management, 69, 135-146. https://www.ama.org/the-definitionof-marketing/ (access 13/04/2019)

23. What is Marketing? - The Definition of Marketing - AMA. (2019). Retrieved from https:// 